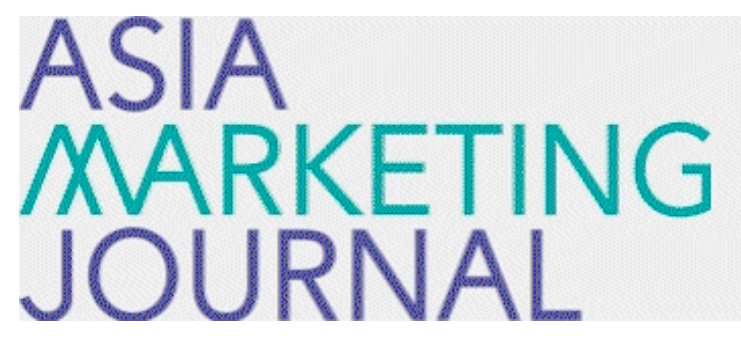

ASIA MARKETING JOURNAL

Volume 18 | Issue 4

Article 2

$1-31-2017$

\title{
An Exploratory Study on the Effect of Price as an Anchor on Willingness-to-pay
}

Jae-Do Song

Follow this and additional works at: https://amj.kma.re.kr/journal

Part of the Marketing Commons

\section{Recommended Citation}

Song, Jae-Do (2017) "An Exploratory Study on the Effect of Price as an Anchor on Willingness-to-pay," Asia Marketing Journal: Vol. 18 : Iss. 4 , Article 2.

Available at: https://doi.org/10.15830/amj.2017.18.4.27

This Article is brought to you for free and open access by Asia Marketing Journal. It has been accepted for inclusion in Asia Marketing Journal by an authorized editor of Asia Marketing Journal. 


\title{
An Exploratory Study on the Effect of Price as an Anchor on Willingness-to-pay: Anchoring-and-adjustment or Selective Accessibility*
}

\author{
Jae-Do Song**
}

\begin{abstract}
The two competing underlying mechanisms of anchoring, anchoring-and-adjustment and selective accessibility, have very different managerial implications for the effect of price as an anchor on willingness-to-pay (WTP). To clarify their relative roles in inducing the anchoring effect, path analysis modeling in which two paths are included in a single model was utilized. The first path proceeds directly from anchor price to WTP, representing anchor-and-adjustment. The second path, representing selective accessibility, includes a mediator formed by various explanatory variables of WTP. The results consistently show that only the direct path, anchoring-and-adjustment, is significant. The results also show that the level of available product information has no significant moderation effect on both of the paths, which implies the robustness of the result with respect to information level.
\end{abstract}

Key words: price, willingness-to-pay, anchoring, anchoring-and-adjustment, selective accessibility

\section{Introduction}

The concept of willingness-to-pay (WTP) as a consumer's target estimate for a product has attracted research attention in relation to anchoring (Ariely, Loewenstein, and Prelec 2003; Mussweiler, Strack, and Pfeiffer 2000; Northcraft and Neale 1987) or as a starting point bias that affects the subsequent evaluation of WTP from the initial offer of price (Alberini, Kanninen, and Carson 1997; DeShazo 2002; van Exel et al. 2006; Whitehead 2002).

The anchoring effect of price implies that firms can increase the WTP of potential customers by setting the price high, specifically for a new product for which people do not have a concrete product evaluation, justifying high in-

\footnotetext{
* This work was supported by the National Research Foundation of Korea Grant funded by the Korean Government (NRF-2014S1A5A2A03064942).

** College of Business Administration, Chonnam National University (sjaedo@chonnam.ac.kr)
} 
troductory prices with a different view point from reference prices (Sitzia and Zizzo 2012). However, there are two competing explanations presented in the literature regarding how anchoring works. The two explanations lead to different implications about the effectiveness of high introductory price utilizing the anchoring effect.

The anchoring-and-adjustment view maintains that consumers make insufficient adjustments to yield a final WTP estimation based on an initially presented value or parameter. As a result, the estimated value is biased toward the anchor value (Furnham and Boo 2011). On the other hand, the selective accessibility view, also known as confirmatory hypothesis testing, advocates that the anchoring effect results from the activation of information that is consistent with the anchor (Furnham and Boo 2011). Therefore, according to this view, consumers consider the anchor as a plausible answer and then verify that the anchor is a reasonable estimate. In doing so, consumers search for ways to justify their WTP value set according to the anchor value by activating only those aspects that explain the target price in a manner consistent with the initial WTP value (Furnham and Boo 2011).

Anchoring-and-adjustment process can be seen as a simple cognitive bias resulting from heuristics (Tversky and Kahneman 1974). In this case, the anchoring effect may not exist when proper information or motivation regarding a real purchase setting is given. Alternatively, in selective accessibility process, consumers consider plausibility of the anchor and try to justify the anchor. In the process, consumers will change beliefs about the product, which is very meaningful from the view of marketing. Further, the selective accessibility process can be seen as a more highly elaborative process (Wegener et al. 2010a, 2010b) which results in enduring attitude change (Baumeister and Bushman 2008, P463; Wood and Hayes 2012). Therefore, selective accessibility view can justify high introductory price better than anchoring-and-adjustment view. Therefore, identifying the prevalent mechanism of anchoring is very important from the view of price strategy.

In identifying the prevalent mechanism, the role of knowledge or expertise has been at the center of the debate (Furnham and Boo 2011). Specifically, scholars generally agree that if knowledgeable people or experts, who have less uncertainty in estimating their WTP price, are still vulnerable to anchoring, selective accessibility may explain the process better (Furnham and Boo 2011). Interestingly the results from the extant studies have been inconsistent. Some researchers show that sufficient information, knowledge, or experience can eliminate the anchoring effect (Chapman and Johnson 1994; DelVecchio and Heath 2012; List 2011), whereas others fail to find such moderating effects (Englich and Mussweiler 2001; Englich, Mussweiler, and Strack 2006; Northcraft and Neale 1987). In 
addressing the inconsistency in the literature more comprehensively, this study makes contributions in two areas. First, this study incorporates several variables like value and quality as the mediators of the anchoring effect on WTP using path analysis model in the study. It is primarily to verify whether an anchor leads to changes in consumers' value and quality perceptions that eventually affect their WTP. If selective accessibility prevails, significant changes in consumer perception on product value and quality, the mediating variables, should be accompanied to justify the anchor value. Under the anchoring-and-adjustment view (Furnham and Boo 2011; Wegener et al. 2010a, 2010b), such changes in the mediating variables should be negligible. Incorporating product quality and attributes as mediators offers an effective way to determine the prevailing anchoring mechanism, while the existing studies use just indirect inferences only (DelVecchio and Heath 2012; Englich and Mussweiler 2001; Englich, Mussweiler, and Strack 2006; Epley and Gilovich 2005; LeBoeuf and Shafir 2009; Northcraft and Neale
1987; Tversky and Kahneman 1974; Wilson et al. 1996).

This study also tries to explore the conditions which change the nature of anchoring effect on WTP. Specifically, this study incorporates information level as a moderator to identify the conditions that trigger the selective accessibility route or anchoring-and-adjustment route as shown in Figure 1. If more information can eliminate the effect of anchoring, price as an anchor has no practical role played in the real purchase situation with a proper level of information. On the other hand, if more information strengthens the selective accessibility route, price as an anchor becomes more meaningful.

\section{Theoretical Backgrounds and Hypotheses}

\subsection{Consumer Willingness-to-pay}

Gall-Ely (2009) defined WTP as the maximum

\section{〈Figure 1〉 Effect of Anchor Price}

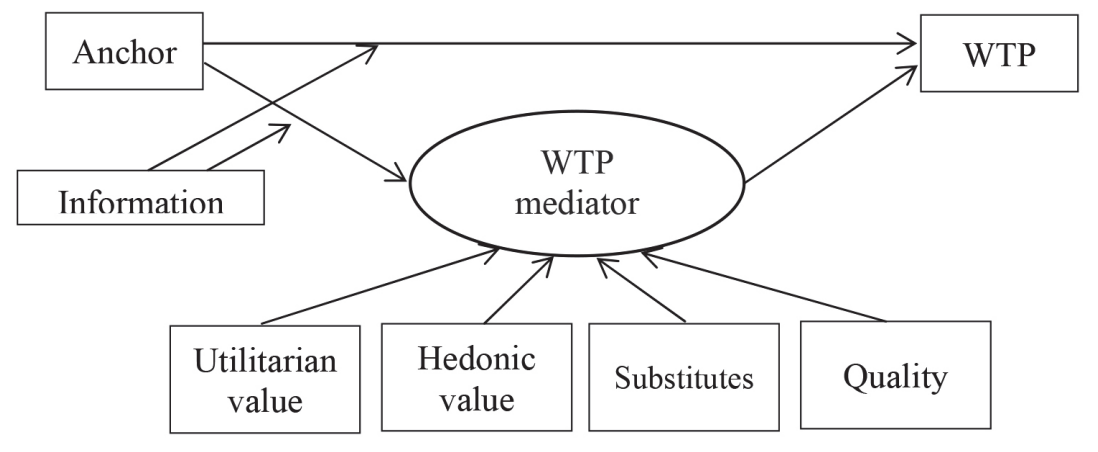


price a given consumer accepts to pay for a product or service. As Monroe (2002, p. 50) and the economics literature have described, WTP reflects the perceived value or utility of a product. Some studies see WTP as a type of reference price (Chandrashekaran 2001; Chandrashekaran and Jagpal 1995), which becomes the standard against which the purchase price of a product is judged (Mazumdar, Raj, and Sinha 2005; Monroe 1973). However, for Thaler (1985), and Bearden et al. (1992), the two concepts differ. Specifically, reference price determines transaction utility and the value of the deal, whereas WTP determines acquisition utility, the net surplus of the utility in dollar terms.

Furthermore, in the traditional economics literature, only WTP is considered because rational decision makers consider only the net surplus. The deal's value or discounted price should just be reflected in the increase in acquisition utility. In this normative rational context, WTP is independent from price or others' evaluations, assuming perfect information and no effect from network externality, symbolic value and so on. Subsequently, WTP is different from reference price, which is affected by experienced prices (Mazumdar, Raj, and Sinha 2005).

This normative rational view may prevent researchers from studying the effect of price on WTP, resulting in no extant studies dealing with the topic from a managerial perspective. The few existing studies have shown only that price as an anchor affects one's evaluation of WTP without considering managerial implications (Ariely, Loewenstein, and Prelec 2003; Mussweiler, Strack, and Pfeiffer 2000; Northcraft and Neale 1987). The starting point bias, which considers the initial offer of price as the determinant of the accompanying level of WTP, is similar to anchoring. However, studies have focused on how the effect can be eliminated in the WTP elicitation (Alberini, Kanninen, and Carson 1997; Carlsson and Martinsson 2001; Cooper, Haneman, and Signorello 2002; DeShazo 2002; Flachaire and Hollard 2007; Herriges and Shogren 1996; Ladenburg 2013; Ryan and Wordsworth 2000; van Exel et al. 2006; Whitehead 2002).

When price has an anchoring effect, a higher price could easily be justified as it induces an enhanced WTP as well as a high reference price. However, the practical meaning of anchoring can be significantly different according to the underlying mechanism of anchoring; selective accessibility or anchoring-and-adjustment. If selective accessibility is prevalent, the effect of price as an anchor induces a change in the WTP through the change of perception on attributes of the product. This change of perception deserves our attention in that such change makes anchoring different from external reference price, which concerns primarily how the purchase price of a product is judged (Mazumdar, Raj, and Sinha 2005; Monroe 1973). In addition, researchers generally agree that highly elaborative processing like selective accessibility (Wegener 
et al. 2010a, 2010b) results in an enduring attitude change (Baumeister and Bushman 2008, P463; Wood and Hayes 2012). In contrast, if the anchoring-and-adjustment view dominates the process, the effect does not accompany the change of perception on attributes of the product and could be a temporary bias (Furnham and Boo 2011; Tversky and Kahneman 1974).

However, for those consumers well familiar with the product, there would be an existing WTP value, so a high price may not result in an increased WTP value. In that case, there would be no anchor effect on the WTP. Supporting this view, previous empirical studies have used non-standardized products such as housing and used cars that usually have uncertainties in their WTP evaluations (Ariely, Loewenstein, and Prelec 2003; Mussweiler, Strack, and Pfeiffer 2000; Northcraft and Neale 1987).

Before discussing the underlying mechanism, explanatory variables of WTP as the mediating path from anchor to WTP are defined first. As Monroe (2002, P50) and the economics literature have described, WTP primarily reflects the perceived value or utility of the product. However, the level of competition may also impact the WTP. According to Chan, Kadiyali, and Park (2007), the level of competition among items reduces the WTP in an auction situation. Subsequently, this study contends that value and competition are the basic determinants of the WTP. To capture the value more effectively in this study, two different concepts of value, utilitarian and hedonic, are adopted. Hedonic products are desired for pleasure, fantasy, and fun, whereas utilitarian products tend to fulfill basic needs or help accomplish functional or practical tasks (Khan and Dhar 2010; Strahilevitz and Myers 1998). In terms of competition, the availability of substitute products is used to measure the extent of competition that subjects perceive.

On the other hand, economic models like the vertical or horizontal differentiation model address quality as a key determinant of WTP or the utility of a product (Tirole 1988, chap 7). Given our primary interest in the role of explanatory variables in the anchoring process as a whole, this study also includes quality as an explaining variable.

To sum up, four explanatory variables are considered in this study: utilitarian value, hedonic value, substitutes, and quality. These collectively covers broad concept of product while directly related to WTP. Any intrinsic consumer evaluation process activated to justify anchor price is expected to accompany changes in some of the four variables. Those explanatory variables are treated as formative indicators (Jarvis, Mackenzie, and Podsakoff 2003; Petter, Straub, and Rai 2007), rather than reflective indicators, of the WTP mediator in the study because each of those variables is expected to be affected by the anchor independently; moreover, those variables are not highly correlated among themselves. 


\subsection{Anchoring Mechanisms}

Furnham and Boo (2011) and Wegener et al. (2010a, 2010b) considered selective accessibility to be a highly elaborative type of anchoring that typically activates the relevant aspects of target estimates. As Mussweiler and Strack (1999) explained, the standard anchoring paradigm comprises two tasks: a comparative judgment task and an absolute judgment task. In a comparative judgment task, subjects are asked to compare a target estimate with an anchor value. According to the selective accessibility view, in the judgment task subjects test the hypothesis that the target estimate is the same as the anchor value, and subjects activate semantic knowledge that justifies the anchor (Mussweiler and Strack 1999). Then, such anchor-consistent knowledge is better accessible and eventually affects the target estimate in an absolute judgment task (Mussweiler and Strack 1999).

If the anchor is the high price and the target estimate is the WTP, subjects may activate only positive attributes like well-known brand and good design, ignoring other aspects like simple function and weak materials. As a result, subjects may form a belief of high value, quality, or less substitutes, which would then lead to a higher estimate in the final absolute judgment. In sum, if a high anchor price results in a high WTP and selective accessibility is prevalent, changes in the explanatory variables of WTP defined will occur.

If an anchor price does not change those explanatory variables but WTP does change, it suggests that anchoring-and-adjustment, an alternative explanation for the anchoring mechanism, is prevalent. Wegener et al. (2010a, 2010b) considered anchoring-and-adjustment a low elaboration anchoring characterized by a nonthoughtful process. In this process, consumers arrived at the conclusion directly through simple priming of the number or the general sense of the magnitude of a target being large or small (Wegener et al. 2010a, p. 8). This means that an anchor price directly affects WTP without changing explanatory variables. In that case, anchoring-and-adjustment can be presented by the direct pathway between anchor and WTP in Figure 1.

Another possible scenario is that both anchoringand-adjustment and selective accessibility occur simultaneously. Anchoring-and-adjustment occurs basically due to uncertainty. If uncertainty remains or subjects have just a vague range of target estimates even after the activation of information that is consistent with the anchor presented, the possibility of anchoring-andadjustment can not be ruled out. Figure 2 illustrates such a scenario. In the figure with the high anchor price, the activation of anchorconsistent attributes, selective accessibility, results in a shift of range $\left(\mathrm{SR}^{\mathrm{A}}\right)$, and insufficient adjustment ( $\mathrm{IA}^{\mathrm{A}}$ ) also occurs because of the remaining uncertainty. 
〈Figure 2〉 Conceptual Presentation of the Anchoring Effect

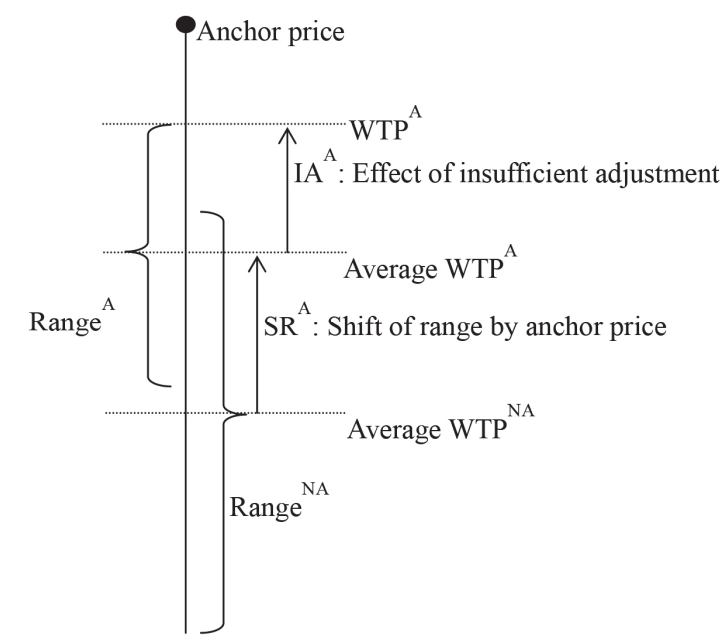

Note: $\mathrm{NA}=$ Non-anchor, $\mathrm{A}=$ Anchor

When a sufficiently high anchor price is given, relative to the case without anchor, two hypotheses are possible.

H1: The anchor price positively affects WTP directly.

H2: The anchor price positively affects WTP through the explanatory variables.

\subsection{Moderating Effect of Information}

Anchoring is viewed as a type of cognitive bias (Tversky and Kahneman 1974). Whenever cognitive bias is present, the assumption of economic rationality is often debated together. Specifically, as preference anomalies like the WTP-WTA (willingness-to-accept) disparity, also called the endowment effect, and preference reversal have been reported (Biel, JohanssonStenman, and Nilsson 2011; Horowitz and McConnell 2002; Plott and Zeiler 2005; Tversky and Thaler 1990), the notion of whether people have a consistent preference becomes an important topic (Braga and Starmer 2005, p. 55). Therefore, the extent to which sufficient information eliminates cognitive bias and/or preference anomalies becomes an interesting subject. Actually, this is very important with respect to the robustness of anchoring and the assumption of economic rationality.

According to the selective accessibility logic, more information can help subjects better search for ways to align the anchor value with their estimate, making the anchoring effect stronger (Furnham and Boo 2011; Wegener et al. 2010a, 2010b). Selective accessibility view anticipates positive moderation of information level. Alternatively, Green et al. (1998, p. 95) argued that "extrapolating the psychometric observation that anchoring effects are weaker when a priori beliefs are stronger, one might expect the strongest anchoring effects when primitive beliefs are weak or absent, and the weakest anchoring effects when primitive beliefs are sharply defined." The strength of belief in this argument is related to the concept of certainty, and more information which reduces uncertainty will negatively moderate the effect of anchor price. This certaintyrelated negative moderation is closely related to anchoring-and-adjustment (Furnham and Boo 2011). A review of the literature reveals that 
the anchoring effect has been negatively associated with certainty (Chapman and Johnson 1994; DelVecchio and Heath 2012; Ladenberg 2013; List 2003, 2004, 2011; Luchini and Watson 2013) and knowledgeable level (Kato and Hidano 2007; Wilson et al. 1996). However, some studies have shown that information do not have a moderating effect differently from the explanation of anchoring-and-adjustment (Englich and Mussweiler 2001; Englich, Mussweiler, and Strack 2006; Englich and Soder 2009; Northcraft and Neale 1987; Wilson et al. 1996).

To sum up, although different explanations of anchoring result in different inferences, the results of empirical studies in the literature have remained inconsistent. The previous literature considers the concept of experience or knowledge rather than information level. In reality, experience or knowledge on a target estimate is inherently a very broad concept. For example, experience with or knowledge of a product may imply information about the product itself, the market value of the product, substitutive products, and so on. In this study, the effect of prior experience and knowledge is excluded by selecting a least-popular product category, and the level of information about the product is controlled.

While previous studies did not consider anchoring-and-adjustment and selective accessibility simultaneously in a single model, this study considers direct and indirect paths each of which represents different view as expressed in Figure
1. The positive moderation from selective accessibility view is only related to the path from anchor to WTP mediator because the search of anchor-consistent information relates to $\mathrm{ex}^{-}$ planatory variables of WTP. Alternatively, the negative certainty-related moderation can occur on both of the direct path to WTP and the path from anchor to WTP mediator. Then, if negative moderation of information level is found on the direct path to WTP, it can be regarded as a support of anchoring-and-adjustment. Alternatively, positive moderation of information level on the path from anchor to WTP mediator supports selective accessibility.

Further, whether these moderation effects are supported or not determines the robustness of each type of anchoring. If the direct path is negatively moderated by information level, anchoring-and-adjustment type anchoring can be meaningless when sufficient information is searched as in real purchase situation. On the other hand, if indirect path is positively moderated, more information can strengthen the selective accessibility type anchoring.

Based on the discussion, the following hypotheses are offered:

H3a: More information will moderate the direct effect of anchor price on the WTP negatively.

H3b: More information will moderate the effect of anchor price on the WTP mediator positively. 
By offering these hypotheses, this study seeks different implications from the effect of price as an anchor on the WTP. If only the direct path, anchoring-and-adjustment, is significant and information negatively moderates the path, the effect of price can be eliminated through consumers learning about the product. Then, the effect has less managerial meaning. However, if the indirect path, selective accessibility, is significant and positive moderation is found, the effect of price would be considered more robust and enduring. In that case, more information can strengthen the effect.

\section{Study 1}

\subsection{Overview of the Study}

Study 1 has a 2 (anchor or no-anchor) $\times 2$ (low or high information) between-subject design. By comparing anchor and no-anchor settings, $\mathrm{H} 1$ and $\mathrm{H} 2$ are tested, and by comparing low and high information, Hypotheses $3 \mathrm{a}$ and $3 \mathrm{~b}$ are tested.

\subsection{Methods}

Subjects in the range of 18 to 60 years of age were recruited using an online panel service, Mechanical Turk. In the beginning of the survey, the purpose of the survey was explained very simply by stating that "We are conducting an academic survey about willingness-to-pay. We need to understand your response to a price." The subjects were paid \$1.0.

Following the typical anchoring process, the product information as shown in Appendix A and $\mathrm{B}$ was first given. The product was explained with only texts in the low-information situation. In this setting, subjects were expected to understand the purpose of the given product, but have an unclear idea about its appearance and how it works. The high-information setting includes a picture that was expected to offer additional information about the product to the subjects. The comparison of the two variables, 'information' and 'understanding, between low- and high-information settings showed a significant difference $(\mathrm{p}<.05)$ as shown in Table 1. The questions used to measure the information level were: "The information provided on the previous page was sufficient to

〈Table 1〉 Manipulation Test of Information Level

\begin{tabular}{ccccc}
\hline & \multicolumn{2}{c}{ Information level } & \multicolumn{2}{c}{ Understanding level } \\
\hline Manipulation & Low & High & Low & High \\
\hline Mean & 4.00 & 4.64 & 4.23 & 4.95 \\
T-value & \multicolumn{2}{c}{$2.07(\mathrm{p}<.05)$} & \multicolumn{2}{c}{$2.54(\mathrm{p}<.01)$} \\
\hline
\end{tabular}


evaluate the value of the product" and "I fully understand the quality of the product and how it works." A 7-point Likert scale was used for these and subsequent questions anchored from 'strongly disagree' to 'strongly agree, with 'not sure' as the midpoint.

Subjects were then asked to answer a yesor-no question in the anchor setting: "A retailer is selling the above product at $\$ 70$. Are you willing to buy this product at this price?" In the no-anchor setting, the same question without the price was used to make both surveys as comparable as possible. Then, on the following page, subjects were asked, "Assume that a retailer offers you to purchase the above product now. What would be the maximum price you are willing to pay for the product above? \$ ." After this page, additional questions were asked.

The product used in study 1 was potato swirler (potato spiral cutter machine). The potato swirler was a low-ranked product at 37,867th in the Amazon Best Sellers Kitchen \& Dining section, and was intentionally chosen given that the level of information about the product should be controlled. Furthermore, some studies suggested the problem of implausible extreme anchors (DelVecchio and Heath 2012; Mussweiler and Strack 2000; Wegener et al. 2001). If an unfamiliar product is chosen, subjects cannot judge the plausibility of the anchor price easily. A pre-test with 8 subjects showed that the average WTP for the product was $\$ 12.50$ and the maximum WTP was \$26. Based on this, the anchor was set at a sufficiently high level at $\$ 70$.

After the subjects filled in their WTP price, they answered a set of questions for the explanatory variables for WTP, measuring the perceived utility and hedonic values, product substitutability, and perceived quality of the given product. Because the role of explanatory variables as a whole is the main concern, the actual responses for each of the variables were not important, relatively speaking. Therefore, these were measured on a single item scale. The actual questions were: "The product shown on the previous page looks useful to me"; "The product offered in this study seems to give pleasure and fun"; "There are better ways or products other than the product"; and "The quality of the product looks good."

Then, additional questions were included to capture the level of information, 'information' and 'understanding'. To control the level of information, subjects who already had prior information about the product were excluded from the study based on their responses to two questions: "Before participating in this study, I had good information and knowledge about this type of product" and "Before participating in this study, I already knew the price level of this product." Those subjects who responded higher than 4 (not sure) on either of those two questions were excluded from the analysis. After this, gender and age were asked. 
Various tools to filter out responses of poor quality were also used. First, a screening question was added to the middle of the additional set of questions. In the anchor setting, we asked in what range the anchor price was. In the noanchor setting, we used a simple attention check question, "If you read this question, please pick the number associated with Strongly Agree" was included. The number of valid responses was 67 in the low information group and 80 in the high information group. Furthermore, the duration of subject participation was measured. If their review time was less than 10 seconds or if the total participation was less than 70 seconds, those were excluded from the analysis as such amount of time is minimum required in responding to all questions adequately $\mathrm{ac}^{-}$ cording to our observations in the interviewbased pretest with three consumers. As a result, 53 responses in the low information group (anchor situation 26, no anchor situation 27) and 61 in the high information group (anchor situation 31, no anchor situation 30) were included in the subsequent analysis.

\subsection{Results}

This study specifies the explanatory variables as formative indicators of the mediator construct called the WTP mediator (Jarvis, Mackenzie, and Podsakoff 2003; Petter, Straub, and Rai 2007). Arithmetic mean of four explanatory variables was used as the WTP mediator to test the hypotheses. The data was analyzed using IBM SPSS Statistics 21.

Table 2 summarizes the results of path analysis using multiple regressions from low-information setting. The results indicate that the anchor have a direct effect on the WTP $(b=.452, p<$ $.01)$. Therefore, H1 is supported. The results further show that the WTP mediator affects the WTP significantly $(b=.394, p<.01)$. However, the anchor did not significantly influence the WTP mediator $(b=.010, p>.5)$. Therefore, H2 is not supported.

The results of path analysis from high-information setting are summarized in Table 3. The tests of $\mathrm{H} 1$ and $\mathrm{H} 2$ in the high-information setting reveal similar results. $H 1$ is supported with $b=$ .321 $(\mathrm{p}<.01)$. The mediator affects the WTP

〈Table 2〉 Results of Path Analysis in Low-information Setting

\begin{tabular}{llrrrrrl}
\hline Dep. variable & Ind. Variable & B & S.E. & Std. B & \multicolumn{1}{c}{ t } & P & $\mathrm{R}^{2}$ \\
\hline \multirow{2}{*}{ WTP mediator } & Constant & 4.398 & .144 & & 30.491 & $.000^{* * *}$ & .000 \\
& Anchor & .015 & .206 & .010 & .074 & .941 & \\
\hline \multirow{2}{*}{ WTP } & Constant & -27.238 & 12.377 & & -2.201 & $.032^{* * *}$ & .363 \\
& Anchor & 16.117 & 4.030 & .452 & 3.999 & $.000^{* * *}$ & \\
& WTP mediator & 9.561 & 2.740 & .394 & 3.489 & $.001^{* * *}$ & \\
\hline
\end{tabular}

$* \mathrm{p}<.1, * * \mathrm{p}<.05, * * * \mathrm{p}<.001$ (all are the same in the following tables). 
〈Table 3〉 Results of Path Analysis in High-information Setting

\begin{tabular}{llrrrrrr}
\hline \multicolumn{1}{c}{ Dep. variable } & Ind. Variable & \multicolumn{1}{c}{ B } & S.E. & Std. B & t & P & $\mathrm{R}^{2}$ \\
\hline \multirow{2}{*}{ WTP mediator } & Constant & 4.108 & .178 & & 23.032 & $.000^{* * * *}$ & .017 \\
& Anchor & .255 & .250 & .131 & 1.017 & .313 & \\
\hline \multirow{2}{*}{ WTP } & Constant & -10.902 & 11.789 & & -.925 & .359 & .245 \\
& Anchor & 14.710 & 5.277 & .321 & 2.787 & $.007^{* * *}$ & \\
& WTP mediator & 7.992 & 2.722 & .338 & 2.936 & $.005^{* * *}$ & \\
\hline
\end{tabular}

significantly with $b=.338(\mathrm{p}<.01)$. The path from the anchor to the WTP mediator is also not significant $(b=.131, p>.05)$.

To test $\mathrm{H} 3 \mathrm{a}$ and $\mathrm{H} 3 \mathrm{~b}$, the interaction effects between information level and other variables are analyzed and the results are summarized in Table 4 and 5. The coefficient of interaction effect between information level and anchor on WTP is negative as anticipated, but is not sig- nificant $(b=-.017, p>.05)$. The interaction effect between information level and anchor on WTP mediator is also insignificant $(b=.068$, p .05$)$ even though the coefficient is positive as expected. Therefore, H3a and H3b are not supported.

Table 4 and 5 also show that the main effect of information level is positively significant on WTP $(b=.210, p<.05)$, but is insignificant on

〈Table 4〉 Interaction Effect of Information Level on WTP

\begin{tabular}{lcccccc}
\hline \multicolumn{1}{c}{ Ind. Variable } & B & S.E. & Std. B & T & P & $\mathrm{R}^{2}$ \\
\hline Constant & -23.201 & 9.313 & & -2.491 & $.014^{* * *}$ & $.309^{+}$ \\
Anchor & 15.357 & 3.387 & .364 & 4.534 & $.000^{* * *}$ & \\
WTP mediator & 8.714 & 2.017 & .361 & 4.321 & $.000^{* * *}$ & \\
Level of Information & 8.860 & 3.398 & .210 & 2.607 & $.010^{* * *}$ & \\
Anchor * Level of Information & -1.406 & 6.785 & -.017 & -.207 & .836 \\
WTP mediator * Level of Information & -1.570 & 4.129 & -.032 & -.380 & .705 & \\
\hline
\end{tabular}

${ }^{+}$Without interaction terms, $\mathrm{R}^{2}=.308$.

〈Table 5〉 Interaction Effect of Information Level on WTP Mediator

\begin{tabular}{lrrrrrr}
\hline \multicolumn{1}{c}{ Ind. Variable } & $\mathrm{B}$ & $\mathrm{S} . \mathrm{E}$. & $\mathrm{Std} . \mathrm{B}$ & $\mathrm{t}$ & $\mathrm{P}$ & $\mathrm{R}^{2}$ \\
\hline Constant & 4.439 & .145 & & 29.830 & .000 & $.021^{+}$ \\
Anchor & .145 & .165 & .083 & .878 & .382 & \\
Level of Information & -.170 & .165 & -.097 & -1.031 & .305 & \\
Anchor * Level of Information & .239 & .330 & .068 & .725 & .470 & \\
\hline
\end{tabular}

${ }^{+}$Without interaction term, $\mathrm{R}^{2}=.016$. 
WTP mediator $(b=-.097, p>.05)$. Combined with the insignificant interaction effect between information level and anchor, this means that more information increases WTP regardless of anchor. Further, the increase of WTP from high level of information is not due to perception of high value or quality. Decreased uncertainty may explain the increase in WTP.

To sum up, Study 1 supports only anchoringand-adjustment process in both of the high and low information situation. Further, no significant moderation effect of information level on direct path means that anchoring-and-adjustment type anchoring is robust with respect to level of information.

\section{Study 2}

\subsection{Overview of the Study}

In Studies 1, the anchor price directly affected the WTP but not the WTP mediator. Such result could probably be attributed to a missing reference product for the subjects to compare. Ariely, Loewenstein, and Prelec (2003, p. 73) suggest the concept of coherent arbitrariness. In their experiment, initial valuation of products is strongly influenced by arbitrary anchors, but subsequent valuations for other products are coherent with respect to differences in perceived quality. The initial valuation has no ref- erence product to compare, but the products previously evaluated can be used as reference products in subsequent valuations. Thus, in subsequent valuations, the differences in WTP reflect the differences in perceived quality. Then, if subjects recall a reference product in estimating WTP with an anchor price, the estimation of WTP can be better correlated to perceived value or quality.

The potato swirler used in Study 1 might be too unfamiliar for subjects to recall a reference product. When a familiar product category is adopted for an experiment, people may use a relative type evaluation for the WTP and explanatory variables by recalling a reference product. Thus, anchor price and WTP mediator would be better correlated, resulting in significant effect from anchor to WTP mediator. To test this inference, a familiar product category is introduced in Study 2 in which subjects may recall a reference product even though the product given is not so familiar.

H4: When a product category is easy for which to recall a reference product, the anchor price positively affects the WTP through the explanatory variables.

\subsection{Methods}

Study 2 adopted an earphone as the experiment product. The product was introduced with text and pictures like in the high-information 
situation of Study 1, as shown in Appendix C. Prior to the experiment, a pretest was run. Using Mechanical Turk, participants answered the following questions after seeing each of the information boxes used in the high-information situation in Study 1 and 2: "I can easily recall a reference product to compare with the above product"; "I can easily recall different brands or products which can do the similar functions with the previous product"; and "I can easily recall substitutive products with the previous product." The same 7-point Likert scale utilized in Studies 1 was used for Study 2.

The reliability of those item scales was consistently high, with a Cronbach's Alpha of .946 for the potato swirler and .933 for the earphone. In addition, the difference in subjects' familiarity between these two products was statistically significant $(t=7.79, p<.01)$. This finding suggests that an earphone represents a good product category with a significantly stronger familiarity among subjects.

As in Study 1, a between-subject experiment with and without an anchor price was conducted. The price on Amazon.com was \$199.99 and appeared sufficiently high relative to the gen- eral earphone, so the anchor price was set at \$199.99. The same WTP elicitation method was used as in Study 1, and the same set of additional questions was included.

In Study 2, information level was not controlled as a moderator. The product category is very familiar and subjects are supposed to understand and evaluate the product information easily. Hence, reducing information level seems to be ineffective.

Subjects were recruited on Mechanical Turk. The method used for data screening was the same as in Study 1. The only exception was that prior product information was not used as a screening criterion because Study 3 did not consider manipulating the product information level. Instead, prior price information was used because the remembered price may decrease the impact of a given anchor price. A total of 72 responses (anchor situation 30, no anchor situation 42) was included in the analysis.

\subsection{Results}

The same model without interaction term as in Study 1 was estimated using IBM SPSS

$\langle$ Table 6〉 Result of path analysis

\begin{tabular}{llrrrrrr}
\hline \multicolumn{1}{c}{ Dep. variable } & Ind. Variable & \multicolumn{1}{c}{ B } & S.E. & Std. B & t & P & $\mathrm{R}^{2}$ \\
\hline WTP mediator & Constant & 5.042 & .117 & & 43.196 & $.000^{* * * *}$ & .020 \\
& Anchor & .217 & .181 & .142 & 1.198 & .235 & \\
\hline \multirow{2}{*}{ WTP } & Constant & -67.640 & 25.917 & & -2.610 & $.011^{* * *}$ & .279 \\
& Anchor & 21.183 & 7.713 & .284 & 2.746 & $.008^{* * *}$ & \\
& WTP mediator & 19.902 & 5.047 & .407 & 3.944 & $.000^{* * *}$ & \\
\hline
\end{tabular}


Statistics 21, and the results are summarized in Table 6. There is a significant effect of anchor on the WTP $(b=.284, p<.01)$. The WTP mediator still affects WTP with $b=.407(p<.01)$. However, there was no significant impact of anchor on the WTP mediator $(b=.142, p>05)$. Hence, H4 is not supported. The results from Study 2 using a familiar product category support only anchoring-and-adjustment process again.

\section{Discussion}

This study investigated the two competing mechanisms of how an anchor affects WTP by incorporating explanatory variables in the study along with the direct path from anchor to WTP together. Particularly, by utilizing path analysis as the analytical tool that is capable of estimating the relationships between multiple independent and dependent variables simultaneously, this study was able to clarify the relative impacts of an anchor on WTP in one model through the two competing explanations as discussed in the literature: anchoring-andadjustment vs. selective accessibility.

The findings include a consistent direct impact of anchor on WTP, supporting the anchoring-and-adjustment view, according to our Studies 1, regardless of the product information level. Even when the product information was manipulated through a familiar product, an earphone in Study 2, consistent results were found. Alternatively, the path from anchor to WTP mediator, which represents selective accessibility process, was insignificant even though the path from WTP mediator to WTP was significant in all settings. This finding is quite significant in that no extant studies have explored both the selective accessibility route and anchoring-and-adjustment route simultaneously. When they are specified simultaneously as in our study, only the anchoring-and-adjustment route consistently remains significant across different settings.

Study 1 also explored moderation effect of information level on both of direct and indirect paths. The result in Study 1 showed no significant moderation effect on any of the paths, even though the directions of moderation were as expected. Information level has just significant main effect on WTP regardless of anchor. This result is also meaningful. Some of previous studies showed negative moderation effect of certainty or knowledge (Chapman and Johnson 1994; DelVecchio and Heath 2012; Kato and Hidano 2007; Ladenberg 2013; List 2003, 2004, 2011; Luchini and Watson 2013; Wilson et al. 1996) and others showed no significant moderation (Englich and Mussweiler 2001; Englich, Mussweiler, and Strack 2006; Englich and Soder 2009; Northcraft and Neale 1987; Wilson et al. 1996). However, those previous studies just considered just a single path from anchor to target estimate without considering two different paths; anchoring- 
and-adjustment and selective accessibility. In this study, the no significant moderation effect of information level on direct path means that anchoring-and-adjustment type anchoring is robust with respect to level of information. On the other hand, no significant moderation on indirect path implies that selective accessibility type anchoring is hard to occur even though level of information increases.

Anchoring-and-adjustment type anchoring, which is supported by this study, has less significant managerial implication than selective accessibility type anchoring. This is because the anchoring-and-adjustment type anchoring does not accompany any change in consumers' perception of product quality. This low-elaborative type of anchoring results in a temporary WTP adjustment according to the elaboration likelihood model (Baumeister and Bushman 2008, P463; Wood and Hayes 2012).

However, we also should notice that Study 1 does not show significant moderation effect of information level on the direct path which represents anchoring-and-adjustment. The result implies that even when customers search extensive information, the anchoring-and-adjustment type anchoring can occur. Therefore, firms can still utilize high introductory price as an anchor which leads customers to high WTP. Estimation of WTP, quantitative monetary value, interacts with the qualitative evaluation of value or satisfaction that consumers perceive with the product. Even though high WTP comes from low-elab- orative heuristics like anchoring-and-adjustment process, the high WTP can has real meaning specifically when customers can find cues for high quality. Some additional cues for high quality or value may complement the high anchor price.

\section{Limitations and Conclusion}

This study provides a consistent support for the anchoring-and-adjustment view rather than selective accessibility when two paths that represent those two views were estimated simultaneously. Even though our results consistently support the anchoring-and-adjustment type of anchoring mechanism, further studies are needed to clarify any conditions that activate the selective accessibility route of anchoring. As Wegener et al. (2010a, 2010b) maintained, it is still possible that both of the two competing mechanisms explain the anchor effect. Existing studies have shown that anchoring actually applies to various target estimates with different characteristics. For example, some studies have dealt with objective target estimates; the mechanism of estimation for objective numbers like the percentage of African countries in the United Nations (Tversky and Kahneman 1974) or the number of students enrolled in a college (DelVecchio and Heath 2012). The process of estimating an objective target would be very different from the process for subjective target estimates like 
the value of a car (Mussweiler, Strack, Pfeiffer 2000), value of a house (Northcraft and Neal 1987), or a judicial sentencing decision (Englich and Mussweiler 2001; Englich, Mussweiler, and Strack 2005, 2006). This study dealt only with a subjective target estimate, WTP. Different results could emerge with other types of target estimates.

Future studies should also examine how permanent the effect of anchoring-and-adjustment type anchoring is. Although there is a change in WTP, quantitative monetary value, as a result of anchoring, it may not necessarily mean that there is an accompanying adjustment in the qualitative evaluation of value or the satisfaction associated with the product as argued by the coherent arbitrariness view. In other words, even though WTP increases, a meaningful change in the intention to purchase or in the value relative to a competing product may not be involved in the process according to our study results. If this is what happens to anchoring, the implications of changes in WTP are vague, and future studies are advised to investigate any boundary conditions that induce a more long-term change in WTP, potentially through the selective accessibility route.

〈Received July 19. 2016〉

〈Revised November 18. 2016〉

〈Accepted January 12. 2017〉

\section{References}

Alberini, Anna, Barbara Kanninen, and Richard Carson (1997), “Modeling response incentive effects in dichotomous choice valuation data," Land Economics, 73(3), 309-324.

Ariely, Dan, George Loewenstein, and Drazen Prelec (2003), "Coherent arbitrariness: Stable demand curves without stable preferences," Quarterly Journal of Economics, 118(1), 73-105.

Baumeister, Roy F., and Brad J. Bushman (2008). Social Psychology and Human Nature. Thomson Wadsworth.

Bearden, William. O., Ajit Kaicker, Melinda Smith de Borrero, and Joel E. Urbany (1992), "Examining alternative operational measures of internal reference prices," Advances in Consumer Research, 19(2), 629-635.

Biel, Anders, Olof Johansson-Stenman, and Andreas Nilsson (2011), "The willingness to pay - willingness to accept gap revisited: The role of emotions and moral satisfaction," Journal of Economic Psychology, 32(6), 908-917.

Braga, Jacinto, and Chris Starmer (2005), "Preference Anomalies, Preference Elicitation and the Discovered Preference Hypothesis," Environmental \& Resource Economics, 32 (1), 55-89.

Carlsson, Fredrik, and Peter Martinsson (2001), "Do hypothetical and actual marginal 
willingness to pay differ in choice experiments," Journal of Environmental Economics and Management, 41(2), 179-192.

Chan, Tat Y., Vrinda Kadiyali, and Young-Hoon Park (2007), "Willingness to pay and competition in online auctions," Journal of Marketing Research, 44(2), 324-333.

Chandrashekaran, Rajesh (2001), "The implications of individual differences in reference price utilization for designing effective price communications," Journal of Business Research, 53(2), 85-91.

Chandrashekaran, Rajesh, and Harsharanjeet Jagpal (1995), "Is there a well-defined internal reference price?," Advances in Consumer Research, 22(1), 230-235.

Chapman, Gretchen B., and Eric J. Johnson (1994), "The limits of anchoring," Journal of Behavioral Decision Making, 7(4), 223242.

Cooper, Joseph C., Michael Haneman, and Giovanni Signorello (2002), "One and one-half bids for contingent valuation," Review of Economics and Statistics, 84(4), 742-750.

DelVecchio, Devon, and Timothy B. Heath (2012), "The effect of dual anchors on numeric judgments: The moderating effects of anchor order and domain knowledge," Advances in Consumer Research, 40, 547-552.

DeShazo, J. R. (2002), “Designing transactions without framing effects in iterative question formats," Journal of Environmental Economics and Management, 43(3), 360-385.
Englich, Birte, and Thomas Mussweiler (2001), "Sentencing under uncertainty: anchoring effects in the courtroom," Journal of Applied Social Psychology, 31(7), 1535-1551.

Englich, Birte, and Thomas Mussweiler, and Fritz Strack (2005), "The last word in court - a hidden disadvantage for the defense," Law and Human Behavior, 29(6), 705-722. (2006), "Playing dice with criminal sentences: the influence of irrelevant anchors on experts' judicial decision making," Personality and Social Psychology Bulletin, 32 (2), 188-200.

Englich, Birte, and Kirsten Soder (2009), “Moody experts - how mood and expertise influence judgmental anchoring," Judgmental and Decision Making, 4(1), 41-50.

Epley, Nicholas, and Thomas Gilovich (2005), "When effortful thinking influences judgmental anchoring: Differential effects of forewarning and incentives on self-generated and externally provided anchors," Journal of Behavioral Decision Making, 18(3), 199212.

Flachaire, Emmanuel, and Guillaume Hollard (2007), "Starting point bias and respondent uncertainty in dichotomous choice contingent valuation surveys," Resource and Energy Economics, 29(3), 183-194

Furnham, Adrian, and Hua Chu Boo (2011), “A literature review of the anchoring effect," Journal of Socio-Economics, 40(1), 35-42. Gall-Ely, Marine Le (2009), “Definition, mea- 
surement and determinants of the consumer's willingness to pay: A critical synthesis and avenues for further research," Recherche et Applications en Marketing (English Edition), 24(2), 91-112.

Green, Donald, Karen E. Jacowitz, Daniel Kahneman, and Daniel McFadden (1998), "Referendum contingent valuation, anchoring, and willingness to pay for public goods," Resource and Energy Economics, 20(2), 85-116.

Herriges, Joseph A., and Jason F. Shogren (1996), "Starting point bias in dichotomous choice valuation with follow-up questioning," Journal of Environmental Economics and Management, 30(1), 112-131.

Horowitz, John K., and Kenneth E. McConnell (2002), “A review of WTA/WTP studies," Journal of Environmental Economics and Management, 44(3), 426-447.

Jarvis, Cheryl B., Scott B. Mackenzie, and Philip M. Podsakoff (2003), “A critical review of construct indicators and measurement model misspecification in marketing and consumer research," Journal of Consumer Research, 30(2), 199-218.

Kato, Takaaki, and Noboru Hidano (2007), "Anchoring effects, survey conditions, and respondents' characteristics: Contingent valuation of uncertain environmental changes," Journal of Risk Research, 10(6), 773-792.

Khan, Uzma, and Ravi Dhar (2010), "Price-framing effects on the purchase of hedonic and utilitarian bundles," Journal of Marketing
Research, 47(6), 1090-1099

Ladenburg, Jacob (2013), “Does gender-specific starting point bias in choice experiments prevail among well-informed respondents: evidence from an empirical study," Applied Economics Letters, 20(17), 1527-1630.

LeBoeuf, Robyn A., and Eldar Shafir (2009), "Anchoring on the "Here" and "Now" in time and distance judgments," Journal of Experimental Psychology, 35(1), 81-93.

List, John A. (2003), “Does market experience eliminate market anomalies?," The quarterly Journal of Economics, 118(1), 41-71.

(2004), "Neoclassical theory versus prospect theory: Evidence from marketplace," Econometrica, 22(2), 615-625.

(2011), "Does market experience eliminate market anomalies? The case of exogenous market experience," American Economic Review, 101(3), 313-317.

Luchini, Stéphane, and Verity Watson (2013), "Uncertainty and framing in a valuation task," Journal of Economic Psychology, 39, 204-214.

Mazumdar, Tridib, S. P. Raj, and Indrajit Sinha (2005), "Reference price research: Review and propositions," Journal of Marketing, 69 (4), 84-102.

Monroe, Kent B. (1973), “Buyers' subjective perceptions of price," Journal of Marketing Research, 10 (1), 70-80. (2002). Pricing: Making Profitable Decisions (3rd ed.). McGraw-Hill. 
Mussweiler, Thomas, and Fritz Strack (1999), "Hypothesis-consistent testing and semantic priming in the anchoring paradigm: A selective accessibility model," Journal of Experimental Social Psychology, 35(2), 136-164.

(2000), "Numeric judgments

under uncertainty: The role of knowledge in anchoring," Journal of Experimental Social Psychology, 36(5), 495-518.

Mussweiler, Thomas, Fritz Strack, and Tim Pfeiffer (2000), "Overcoming the inevitable anchoring effect: Considering the opposite compensates for selective accessibility," Personality and Social Psychology Bulletin, 26 (9), 1142-1150.

Northcraft, Gregory B., and Marharet A. Neale (1987), "Experts, amateurs, and real estate: An anchoring-and-adjustment perspective on property pricing decisions," Organizational Behavior and Human Decision Processes, 39(1), 84-97.

Petter, Stacle, Detmar Straub, and Arun Rai (2007), "Specifying formative constructs in information systems research," MIS Quarterly, 31(4), 623-656.

Plott, Charles R., and Kathryn Zeiler (2005), "The willingness to pay-willingness to accept gap, the "Endowment Effect," subject misconceptions and experimental procedures for eliciting valuations.", American Economic Review, 95(3), 530-545.

Ryan, Mandy S., and Sarah Wordsworth (2000),
"Sensitivity of willingness to pay estimates to level of attributes in discrete choice experiments," Scottish Journal of Political Economy, 47(5), 504-524.

Sitzia, Stefania, and Daniel John Zizzo (2012), "Price lower and then higher or price higher and then lower?," Journal of Economic Psychology, 33(6), 1084-1099.

Strahilevitz, Michal A., and John G. Myers (1998), "Donations to charity as purchase incentives: How well they work may depend on what you are trying to sell," Journal of Consumer Research, 24(4), 434-446.

Thaler, Richard (1985), "Mental accounting and consumer choice," Marketing Science, 4(3), 199-214.

Tirole, Jean (1988). The Theory of Industrial Organization (8th ed.). The MIT Press.

Tversky, Amos, and Daniel Kahneman (1974), "Judgment under uncertainty: Heuristics and biases," Science, 185(4157), 1124-1131. Tversky, Amos, and Richard H. Thaler (1990), "Anomalies: Preference reversals," The Journal of Economic Perspectives, 4(2), 201-211.

van Exel, N. J. A., W. B. F. Brouwer, B. van den Berg, and M. A. Koopmanschap (2006), "With a little help from an anchor: Discussion and evidence of anchoring effects in contingent valuation," The Journal of SocioEconomics, 35(5), 836-853.

Wegener, Duane T., Richard E. Petty, Brian T. Detweiler-Bedell, and W. Blair G. Jarvis 
(2001), "Implications of attitude change theories for numerical anchoring: anchor plausibility and the limits of anchor effectiveness," Journal of Experimental Social Psychology, 37(1), 62-69.

Wegener, Duane. T., Richard E. Petty, Kevin L. Blankenship, and Brian Detweiler-Bedell (2010 a), "Elaboration and numerical anchoring: implications of attitude theories for consumer judgment and decision making," Journal of Consumer Psychology, 20(1), 5-16. (2010 b), "Elaboration and numerical anchoring: Breadth, depth, and the role of (non-)thoughtful processes in anchoring theories," Journal of Consumer Psychology, 20(1). 28-32.
Whitehead, John C. (2002), "Incentive incompatibility and starting-point bias in iterative valuation questions," Land Economics, 78 (2), 285-297.

Wilson, Timothy D., Christopher E. Houston, Kathryn M. Etling, and Nancy Brekke (1996), "A new look at anchoring effects: basic anchoring and its antecedents," Journal of Experimental Psychology: General, 125 (4), 387-402.

Wood, Wendy, and Timothy Hayes (2012), "Social influence on consumer decisions: Motives, modes, and consequences," Journal of Consumer Psychology, 22(3), 324-328. 
Appendix A. Product Information Used in the Low Information Situation in Studies 1

\section{Potato Swirler}

- Spiral vegetable cutter

- It features a tornado or spiral shaped cutter that is great for home use or at a restaurant.

- Make curly fires, twisted potato chips and veggie snacks

- Features: Stainless steel construction; Low maintenance; Non-slip rubber feet; Simple operation

- Overall dimensions: $10.25^{\prime \prime}(\mathrm{L}) \times 4.5^{\prime \prime}(\mathrm{W}) \times 5.5^{\prime \prime}(\mathrm{H})$; Handle and cutter: 11.5";

Appendix B. Product Information Used in the High Information Situation in Studies 1

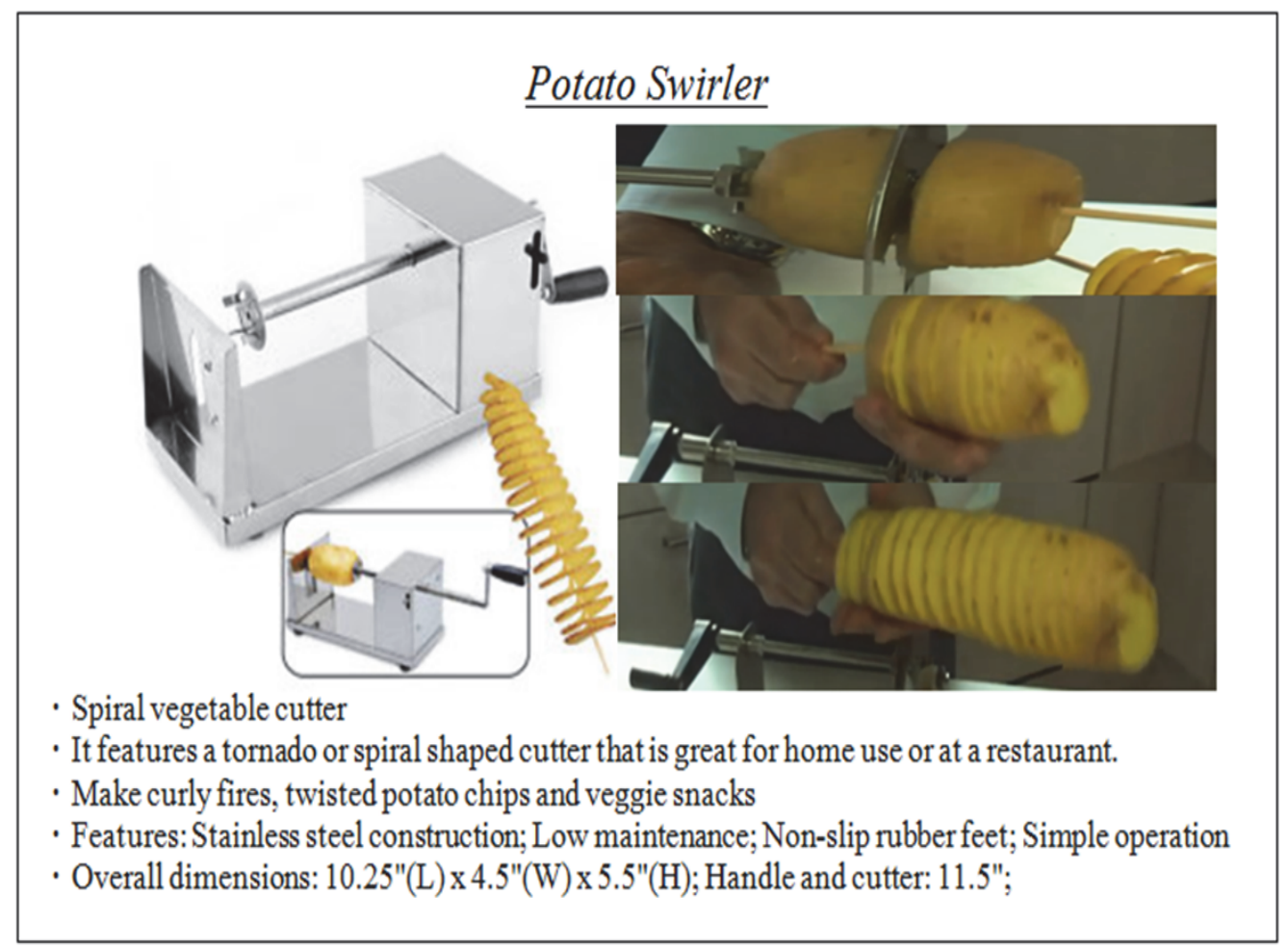


Appendix C. Product Information Used in Study 2

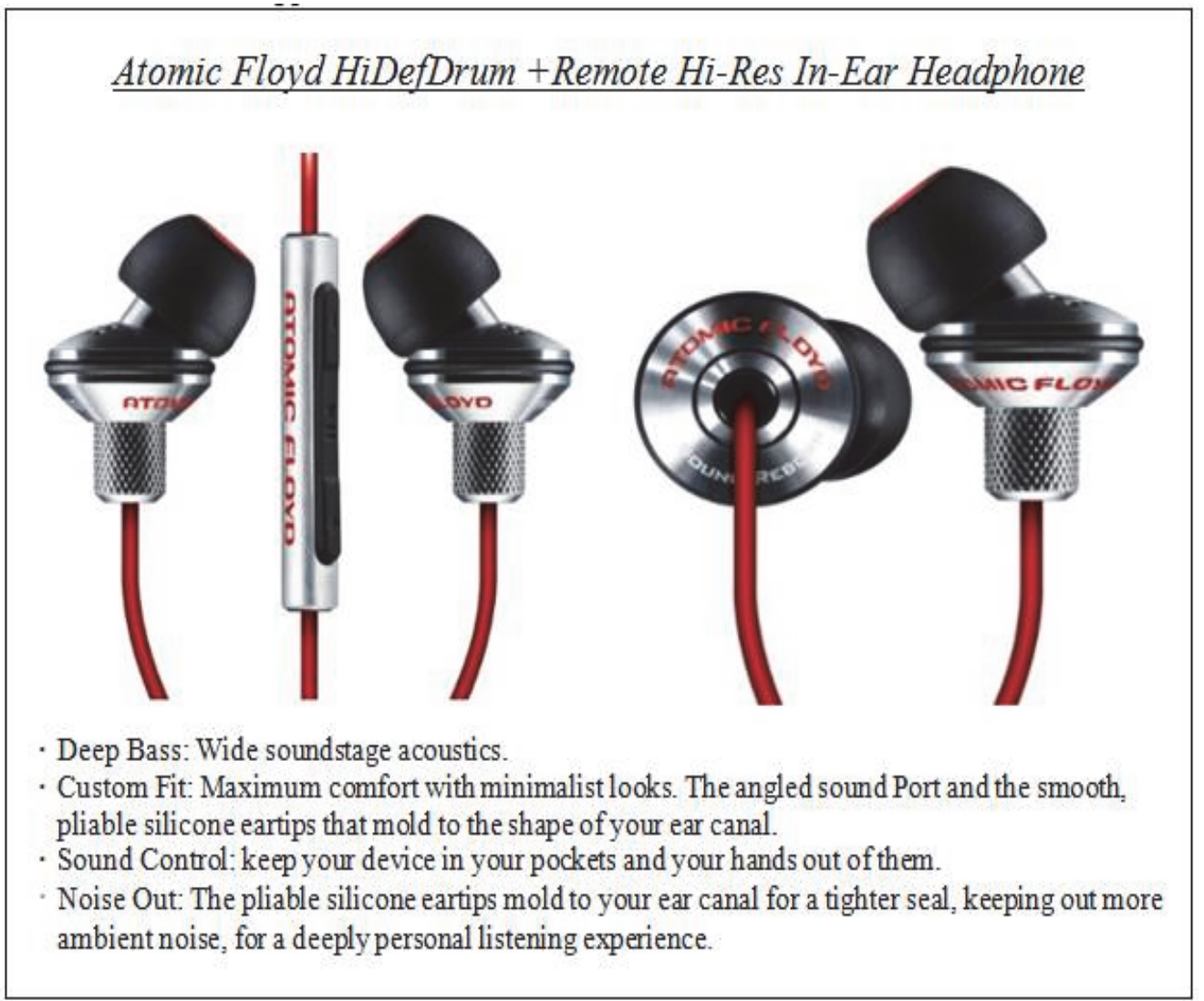

